\title{
Facilitating parent-teenager communication through interactive photo cubes
}

\author{
Connie Golsteijn • Elise van den Hoven
}

Received: 17 March 2011 / Accepted: 28 October 2011/Published online: 4 December 2011

(C) The Author(s) 2011. This article is published with open access at Springerlink.com

\begin{abstract}
Because most teenagers strive for freedom and try to live autonomously, communication with their parents could be improved. It appeared from a literature review and a diary study that parent-teenager communication primarily addresses teenager-oriented everyday activities. However, it also showed teenagers have a substantial interest in getting to know their parents and their parents' past. The study described in this paper seeks to address this opportunity by designing a product for parents and teenagers that facilitates communication about the past of the parents. The resulting design, called Cueb, is a set of interactive digital photo cubes with which parents and teenagers can explore individual and shared experiences and are triggered to exchange stories. An evaluation of a prototype of Cueb with four families showed that the participants felt significantly more triggered and supported to share their experiences and tell stories with Cueb's full functionality (connecting cubes, switching, and locking photographs) than with limited functionality (shaking to display random photographs), similar to more traditional photo media.
\end{abstract}

Keywords Parent-teenager communication - Digital photographs · Everyday remembering · Sharing memories . Design research $\cdot$ Interaction design

Electronic supplementary material The online version of this article (doi:10.1007/s00779-011-0487-9) contains supplementary material, which is available to authorized users.

C. Golsteijn $(\bowtie) \cdot$ E. van den Hoven

Department of Industrial Design,

Eindhoven University of Technology,

P.O. Box 513, 5600 MB Eindhoven, The Netherlands

e-mail: info@conniegolsteijn.com

E. van den Hoven

e-mail: e.v.d.hoven@tue.nl

\section{Introduction}

Early adolescence is an important transitional period in the development of a child. On the one hand, the child strives for independence, while on the other hand, (s)he is still in need of a warm and close relationship with her or his parents [1]. Good and open family communication can contribute much to this relationship, to the child's development, and its self-esteem [2]. However, adolescence is typically a period in which communication problems between parents and children arise, such as arguments [3] or reluctance to discuss certain topics, for example, sexuality [e.g., 4, 5]. These are not the only problems, however; according to Richardson [6], parents and teenagers have quite different views on what needs to be the subject of communication, leading to mismatches in actual and desired communication. Richardson states that parentteenager communication support may benefit from less focus on adolescent problem prevention and more focus on the topics teenagers want to discuss. Her study with 1,124 teenagers showed that these topics include the parent-child relationship and getting to know their parents and their parents' past. These findings were taken as a starting point in our study that aimed at supporting communication between parents and young teenagers (aged 10-15). Through the design of an interactive product, we aimed at facilitating parent-teenager communication about the parents' past. This study was done through a design research approach-an approach combining product design and scientific research by using research methods to conduct experiments and draw knowledge from prototypes [7]. Our literature review allowed us to identify the stated design focus, and our study was continued with a validation of the literature findings on parent-teenager communication through a diary study (Sect. 3), the design of Cueb (Fig. 1), 
an interactive photograph device (Sect. 4), the implementation (Sect. 5), and a user evaluation of the design (Sect. 6). This paper ends with a discussion and conclusion of our findings (Sects. 7 and 8). But first, we will address related work in the fields of psychology, HCI, design, and engineering.

\section{Related work}

Early adolescence (age 10 through 14) is an important transitional period in the development of a child. In this period, the child experiences physical changes (e.g., hormonal processes), cognitive changes (e.g., the emergence of abstract thinking abilities), and social transitions (e.g., new social expectations and social role definitions) [6]. In this time of change, most adolescents need and want a warm, close relationship with their parents, to be able to talk to them about problems and issues in their lives [8]. Yet, at the same time, in early adolescence, parents and children begin to spend less time together, because children strive for freedom and independence. This period may be a time when parents and children have more difficulties communicating [6, 9]. To identify opportunities for improvement of parent-teenager communication, it is important to know what parents and teenagers actually communicate about and where difficulties may arise. Surprisingly, despite the considerate amount of research on the importance of good communication habits for the child's development [e.g., 2, 9] and specific processes of communication [e.g., 1,3], there is little information on the actual topics of conversation between teenagers and parents. Most research on parent-adolescent communication has used a topic-specific approach, in which data was collected on communication about a particular topic, especially health-related topics, such as sexuality [e.g., 10, 11] or tobacco, alcohol, and drug use [e.g., 12]. As an exception, a study by Noller and Bagi [1] showed what topics adolescents talked about with their parents. It appeared that parent-teenager communication was often

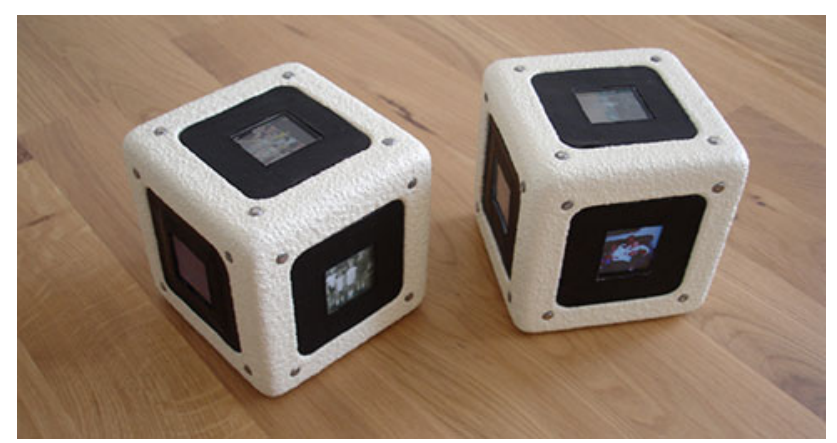

Fig. 1 The prototype of Cueb about interests, plans, and general problems and focused on teenager-oriented issues much more than parent-oriented issues. Parents and teenagers both initiated these teenageroriented talks. This led us to wonder whether this corresponds with the desired communication topics. Richardson [6] studied what topics adolescents actually wanted to talk about with their parents by asking: "If you could ask your mom or dad any question and know you would get an honest answer, what question would you ask?" The results showed the highest percentage of answers (43.6\%) were related to the family, with 'parent-child relationship' $(15.6 \%)$ being the largest category in this group, followed by "getting to know my parent" (13.3\%), "parents" [mutual] relationship" (8.7\%), and "family history" $(2.4 \%)$. From this, it can be concluded that teenagers have the wish to know more about their parents and their family relations, and they are strongly interested in discussing these issues with their parents. It can further be concluded that despite the fact that teenagers are interested in discussing their parents, and in getting to know them better [6], most parent-teenager conversations are about the teenagers [1]. Therefore, there appears to be a mismatch in desired and actual communication, which we considered an interesting direction for the design of an interactive product. Based on this literature overview, we formulated the goal to design an interactive product or system to facilitate parent-teenager communication about the parents' past.

\subsection{Communication applications}

Family communication is a prominent topic of research, and several interactive products and systems have been proposed to support communication in families. One way to do this is by explicitly encouraging family members to express their feelings and relations and reflect on them using interactive devices, as for example, Fida [13], Photoswitch [14], Communicube [15], and Cherish [16] do. More implicitly, family communication in the home can be supported through the use of games or game elements, such as the Family Contract Game [17] and Age Invaders [18]. A third category of support consists of devices that support communication with family members outside the home, for example, ASTRA [19] and Digital Family Portraits [20]. Most of these examples do not have the aim to support in-home communication between teenagers and parents, for example, they were designed to support reflection [15] or narratives [16], solve family disputes [17], close intergenerational gaps [18], or increase awareness of remote family members [19, 20]. Two exceptions are Fida [13], a small device that encourages communication between young teenagers and divorced parents by allowing them to record messages and convey their feelings to their parents, and Photoswitch [14], a novel photo display that encourages 
negotiation and reflection on photograph display between parents and teenagers through limited control mechanisms. However, Fida aims at divorced parents and Photoswitch focuses on encouraging communication about the photographs to display, so none of these examples resembled our design goal. To further specify our goal, our study continued with a literature review of work done on memories and digital photograph applications.

\subsection{Memories}

To be able to discuss their past with their teenagers, the design must be able to facilitate parents to remember events from their past. Autobiographical memory (AM) is the memory for the events in one's life [21], which is a memory system that is constantly adapting its connections between concepts. Remembering an event happens according to a reconstruction process that follows the strongest connections [22]. This approach implies that a memory itself cannot be stored, because the memory is recreated by its owner. In order to help people reconstruct memories, cues can be used. A cue is a stimulus that can help someone to retrieve information from memory if the cue is related to the to-be-retrieved memory. Most used stimuli are photographs, smells, or text labels, but anything can be a cue as long as there is a link between the cue and the to-be-retrieved memory. Such cues can be stored in a so-called augmented memory system, a system that helps people to recollect memories [23]. An overview by Van den Hoven and Eggen [23] has shown that browsing through digital photographs is often the basis of an augmented memory system. Since in our study we used digital photographs as cues, we will give some examples of digital photograph-based memory applications. We focus on co-present photo sharing or storytelling, as categorized by Frohlich et al. [24].

\subsection{Digital photograph applications}

A range of co-present digital photo-sharing applications have been developed over the years. Some focus on mobile devices, such as Storytrack [25] and Memento [26], while others use digital tabletops and are not mobile at all, such as Personal Digital Historian [27] and Family Archive [28]. There are also applications that combine fixed and mobile elements, such as the Digital Photo Browser [29] and Souvenirs [30]. These examples aim at sharing photographs locally or remotely [25], supporting reminiscence [26], facilitating face-to-face story sharing [27], archiving memorabilia [28], or linking physical artifacts to digital photographs [29, 30]. From these examples and the work done on memory retrieval, we can conclude that photographs are an often used and effective medium to help people retrieve memories related to those photographs. However, apart from being used for memory retrieval, photographs can have other functions when placed in the home, for example, expressing family ideas. Swan and Taylor [31] have examined photo displays in the homes of six families and called attention to the finding that families express themselves in their display of photographs, and photo displays come to enact specific ideas of family and home. They propose three concepts of digital photo displays that remain sensitive to the ways photograph displays are currently used in homes, for example, a photo mosaic that can display both photograph collections and single photographs. Photo displays can further be used to support in-home communication and social interaction [e.g., 14, 16]. Finally, Durrant et al. [32] looked at curation of photographs in the home and found that while teenagers comply with the curation mainly done by mothers, they also develop additional, "unsupervised" ways of presenting themselves and their families online. As part of designing our photo device, in the next section, we explain how we gathered more data concerning parent-teenager communication through a diary study.

\section{Diary study}

Through a diary study, we wanted to collect qualitative data and everyday examples of parent-teenager communication and we wanted to identify design opportunities.

\subsection{Method}

There are many possible ways of studying parent-teenager communication, and in the past decades, researchers have acknowledged the advantages of new methods, such as observational methods (e.g., video-taped conversations) and ethnographic methods (e.g., interviews and focus groups) [11]. Also multiple perspectives within a study can give more reliable results, since parents' and teenagers' views on their communication tend to be different [33]. Self-report methods, such as diaries, can be useful to identify typical behavior and perception of communication [3]. Furthermore, diary studies can be used to have individual records, on a daily basis, of any instances of communication, about specific topics or communication in general [11]. By using diaries, reports from multiple family members can be compared and validated. In our study, we used diaries, because we were interested in qualitative information on typical behavior, perception of communication, and multiple views on communication. The diaries were used to gather information on parent-teenager communication, for example, topics of communication and where difficulties may arise. Each family member had his 
or her own diary to complete. These diaries consisted of a number of general questions, which addressed, for example, preferred moments and topics of communication, and communication difficulties, and a number of daily questions, including topics of conversation, initiation, with whom, when, where. The daily questions were answered using illustrations, see Fig. 2. The families were asked to fill out the diaries during a two-week period and choose two communication moments per day to document. The diaries and an explanation of the study were mailed to the families after a telephonic introduction.

\subsection{Results}

Communication diaries were filled out by four Dutch families, all two-parent families with at least one teenager. Diaries were filled out over a time span of 2 weeks, by both parents and one or two adolescent children in each family, see Fig. 3 for the family structures, the family members' ages, and participation in the diary study. In total 14 diaries were returned, which were completed by four fathers, four mothers, four adolescent men, and two adolescent women. Of the 227 conversations reported in this study, fathers contributed $28 \%$, sons $28 \%$, mothers $25 \%$, and daughters $20 \%$ of the conversations.

Many reported conversations were brief and $58 \%$ of the conversations took less than $10 \mathrm{~min}$, such as a 5-min conversation reported by the father in family 2: "Our daughter came back from her korfball game and she enthusiastically reported on the match." The duration of conversations ranged from 1 to $50 \mathrm{~min}$, with an average duration of $8.7 \mathrm{~min}$. The longest reported conversation addressed the experiences of a visit to a monastery of a son. In the setup of this study, family members could choose for themselves which conversations they wanted to report, and they were encouraged to decide this individually (without discussion). Conversations that were reported by multiple family members were combined into one conversation report, leaving the unique conversations for each family. The total number of unique reported conversations was 161 .

Most conversations took place in the afternoons (38\%) and evenings (37\%), such as conversations about school, homework, and diner, followed by mornings $(22 \%)$ and nights (1\%). Most conversations took place in the kitchen $(35 \%)$, followed by outside home $(21 \%)$, in the living room $(17 \%)$, and in a car or on a bike $(8 \%)$, such as conversations about school and politics. The high number for "outside home" was also influenced by the holidays of two of the participating families. Although for these families the holiday apartment was counted as home in the holiday period, conversations also took place on ski runs and terraces, and in restaurants.

The diary study further showed that most conversations were initiated by mothers (29\%) and fathers (29\%), while sons and daughters initiated 12 and 14\%, respectively. A mother, for example, initiated a conversation in this way: "I had found a leaflet of one of the board games the kids had been playing with friends so I asked them how their evening had been." Sons and daughters did end most conversations with percentages of 27 and 24\%, for example, because they "switched to a different topic," or because they left to prepare for sports, school, jobs, or music lessons, or simply because they "had nothing more to say". Fathers and mothers both only ended $14 \%$ of the conversations. So, it could be seen that parents tended to start conversations and teenagers tended to end them.

\subsubsection{Topics and process of communication}

The 161 unique reported conversations were analyzed on topic of communication. Coding was done by a single coder, but to get a consistent list of codes, conversation topics were categorized using open coding, after which
Fig. 2 Participants were asked to draw and write communication location, time, duration, participants, subject, initiation, and termination in this illustrated situation

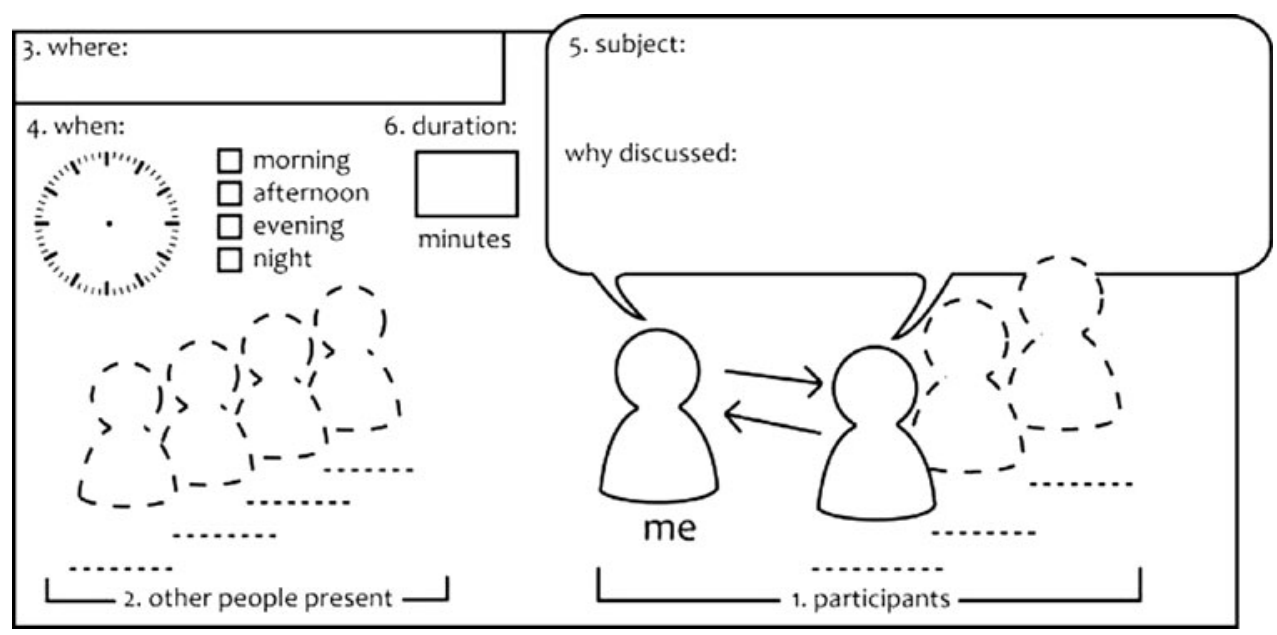


Family 1 - 52 reports

\begin{tabular}{|cc|}
\hline Father (43) & Mother (39) \\
14 reports & 21 reports \\
Daughter (12) & Son (9) \\
17 reports & - \\
& \\
\hline
\end{tabular}

Family 2 - 87 reports

\begin{tabular}{|cc|}
\hline Father (48) & Mother (49) \\
27 reports & 13 reports \\
Daughter (15) & Son (17) \\
28 reports & 19reports \\
Daughter (19) & \\
\hline
\end{tabular}

Family 3 - 51 reports

\begin{tabular}{|cc|}
\hline Father (53) & Mother (49) \\
13 reports & 12 reports \\
Son (16) & Son (14) \\
17 reports & 9 reports \\
Son (8) & \\
- & \\
\hline
\end{tabular}

Family 4 - 37 reports

\begin{tabular}{|cc|}
\hline Father (66) & Mother (46) \\
9 reports & 10 reports \\
Son (17) & Daughter (14) \\
18 reports & - \\
Son (19) & Son (8) \\
- & - \\
\hline
\end{tabular}

Fig. 3 Overview of families in the diary study and the numbers of reported conversations per family and family member ('-'indicates a family member did not participate in the study)

codes were compared and synchronized across families and compared to codes from literature $[1,6]$. There were 14 code categories: Activities, Planning, Interests, School, People and social issues, Feelings, Discussions, Tasks, Material needs, Politics, Religion, Alcohol and drugs, Sex and birth control, and Health, see Table 1. Most conversations $(35 \%)$ were about Activities, of which most conversations addressed suggestions for activities (14\% of all conversations), for example, father family 2: "I asked my daughter if she wanted to come to visit her grandparents, because she hasn't been there for a while", followed by past activities (short term) (8\%), for example, father family 3: "Our son just came back from a school visit to a monastery and we discussed his experiences there", and upcoming activities (short term) (8\%), for example, mother family 2: "We had a nice conversation about the upcoming holiday, because the kids were looking forward to it." Further topics that were addressed often were Planning $(6 \%)$, of which most addressed short-term planning $(14 \%$ of all conversations), School (15\%), of which $12 \%$ addressed current school and 3\% future school, Discussions $(9 \%)$, and Tasks $(8 \%)$.

In almost all of the conversations, family members indicated the conversation "went well" was "peaceful" or "smooth" or that they "reached a consensus quite fast". Only in a few conversations reports included things like: "he did not want to listen," or "through numerous claims of 'it is!', 'it is not!' we reach a conclusion." Discussions and disagreements took place in various topic categories, such as a mother on short-term planning: "We talked about taking care of things yourself. There is always something with our kids: oversleeping, flat tires, lost bus cards, but we are not a taxi company and can't take them to school by car all the time", or a son on discussions: "My mom thought my brother and I spend too much time at the computer and she said that during the holiday the computer should remain switched off, but we didn't agree." Almost all of these conversations, however, were also concluded by reaching a consensus or making an agreement. Parents and teenagers also indicated they think they listen to each other well most of the times, although one father commented: "Most of the times we listen well. Sometimes conversations can escalate and then it is better to take a time-out" and another father commented: "Not always, I don't communicate very comprehensibly." Almost all parents and teenagers indicated there were no topics they wanted to talk about, but were not addressed, and there were no topics they found difficult to discuss with the other party. However, a topic that was commented on by both parents and teenagers was sex. A father stated: "The kids are reluctant to discuss things like being in love, sex, etc. They rather discuss this with peers or brother or sister" and a son stated: "sex; that is rather private." Both parents and teenagers indicated to be satisfied with the communication with the other party: "The communication goes well. I think it is 'normal' in any parent-teenager relationship to encounter difficulties now and then" (a father).

\subsubsection{Discussion and conclusion}

The setup of this study may have had small limitations related to what type of information was collected. First of all, it could be the case that actual arguments were not reported or played down. Secondly, the diaries only provided information about communication that did take place and not about communication that may have been desirable. Although the general questions addressed desired communication, most respondents did not provide much information about this. Despite these drawbacks, the diaries did provide useful insights in the topics of communication, when and where communication takes place, and the duration and processes of these conversations. The reported topics of communication were mostly teenageroriented (e.g., teenagers' activities or school) and possible points for improvement, or design opportunities, could be derived.

1. There were no conversations reported about family relations and getting to know each other, while from literature [6], it appeared adolescents are interested in this. Further, the diaries confirmed the findings from literature [1] that communication was generally teenager-oriented. It may be a good idea to stimulate communication aimed at getting to know each other, 
Table 1 Topics of communication, the absolute number of reports $(N)$, and the same number in percentages $(\%)$ of the total number of conversations

\begin{tabular}{|c|c|c|c|c|c|}
\hline Topic & $N(\%)$ & Topic & $N(\%)$ & Topic & $N(\%)$ \\
\hline Activities & $56(34.8)$ & Discussions & $14(8.7)$ & People and social issues & $5(3.1)$ \\
\hline Suggestion & $22(13.7)$ & Arguments & $7(4.3)$ & Friends & $2(1.2)$ \\
\hline Past (short term) & $12(7.5)$ & Agreements & $7(4.3)$ & Family members & $2(1.2)$ \\
\hline Upcoming (short term) & $12(7.5)$ & Tasks & $12(7.5)$ & Relationships & $1(0.6)$ \\
\hline Current & $6(3.7)$ & Interests & $9(5.6)$ & Alcohol and drugs & 3 (1.9) \\
\hline Upcoming (long term) & $3(1.9)$ & Sports & $6(3.7)$ & Sex and birth control & $2(1.2)$ \\
\hline Past (long term) & $1(0.6)$ & Going out & $2(1.2)$ & Health & $2(1.2)$ \\
\hline Planning & $25(15.5)$ & Job & $1(0.6)$ & Material needs & $1(0.6)$ \\
\hline Short term & $23(14.3)$ & Feelings & $6(3.7)$ & Politics & $1(0.6)$ \\
\hline Long term & $2(1.2)$ & Fear & $2(1.2)$ & Religion & $1(0.6)$ \\
\hline School & 24 (14.9) & Gratitude & $1(0.6)$ & & \\
\hline Current & $20(12.4)$ & Grief & $1(0.6)$ & & \\
\hline \multirow[t]{2}{*}{ Future } & $4(2.5)$ & Doubt & $1(0.6)$ & & \\
\hline & & Frustration & $1(0.6)$ & & \\
\hline
\end{tabular}

oriented toward the parents or both parents and teenagers.

2. Everyday conversations appear to go well if there is someone there for the child, for example, after school. What if there is no one; will the conversations take place anyway? It appears conversations are often based on availability rather than actively looking for each other to communicate.

3. "Heavy topics," such as sex, alcohol, or drugs, were not often discussed, possibly because we only used a two-week window, but it may still be an attention area.

The diary study strengthened our belief in the validity of designing for parent-oriented communication. It confirmed most conversations were about mundane and teenageroriented topics, while parents and teenagers did get along well and indicated to be interested in each other and in getting to know each other better. While literature tends to focus on topic-specific studies, such as sexuality [e.g., 10, 11] or tobacco, alcohol, and drug use [e.g., 12], our study showed these are not the topics of everyday communication. Everyday communication appeared to be much more mundane, and we identified no major concerns in such everyday conversations. While we are aware of the diversity and range of addressing parent-teenager communication, such as health-related and problem-predicting behavior (e.g., sex, drugs, alcohol, and smoking), with whom to communicate [e.g., 34], openness of communication [e.g., 2], and importance of communication [e.g., 35, 36], we decided to focus on a specific topic within this domain, focusing in the first place on more everyday communication. We set out to design a product for parents and teenagers that facilitates communicating in a pleasant way about the parents' past and experiences. With this product or system, the teenagers should also be actively involved, rather than just having to listen to their parents' stories, to prevent boredom.

\section{Design}

Brainstorm sessions were used to generate ideas that could fulfill the design goal. After an initial selection round, based on feasibility and innovation, four concepts were chosen and further developed to use in a user consultation.

\subsection{Concepts}

(a) With the News Bulletin (Fig. 4a), families can look up information about a certain topic or year and store articles that mean something to them in a family archive. These articles can provide a trigger to talk about something and share experiences from the parents' past.

(b) The Conversation Cubes (Fig. 4b) are interactive photo devices family members can use to explore their photograph collections. Each family member has a personal cube with personal photographs, but by connecting two cubes, photographs of shared experiences can be viewed.

(c) The Dusty Photographs concept (Fig. 4c) consists of a series of photo frames in which family members are displayed in different life phases. A person's photograph becomes dusty if the photograph is not communicated about enough. This photograph then needs to be reactivated in order to prevent the frame from obscuring the photograph, which aims to trigger 
Fig. 4 Concept drawings for a News Bulletin, b conversation cubes $\mathbf{c}$ dusty photographs and d timeline
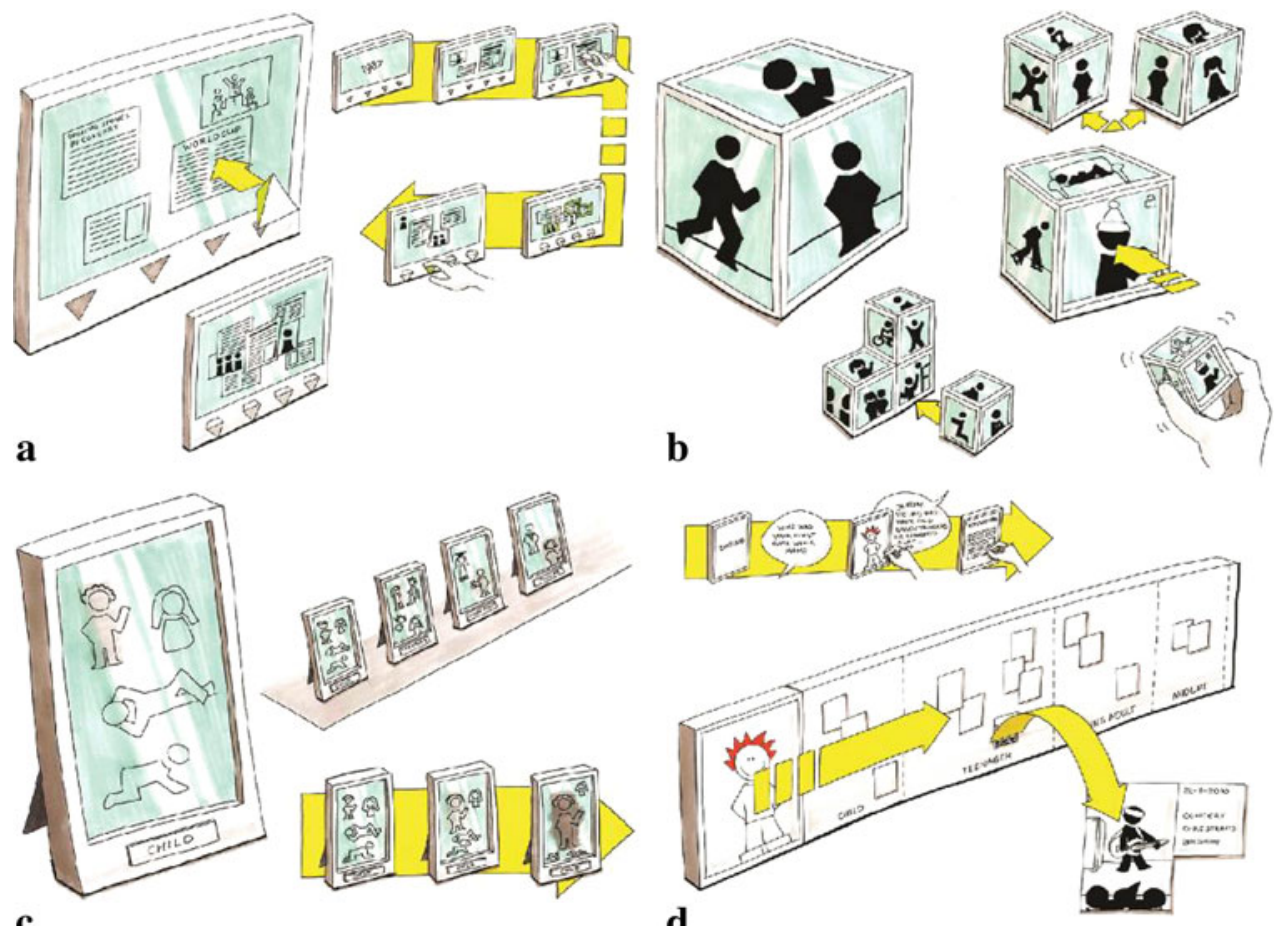

c

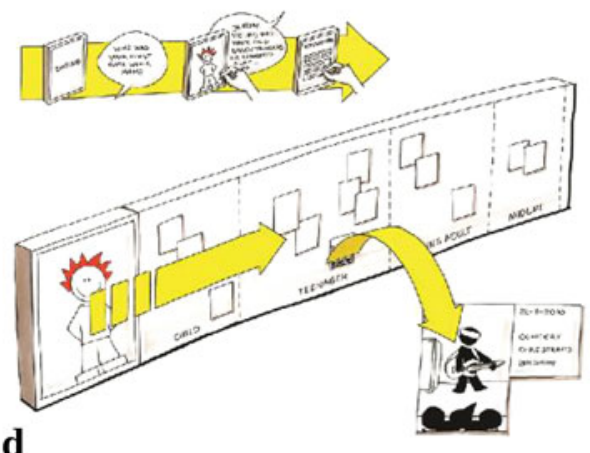

conversations about different persons in different life phases.

(d) The Timeline (Fig. 4d) provides children with subjects to ask questions about. The parent answers the question while the child makes a drawing about the story. Drawings are stored on the Timeline and can be looked back at later to relive stories and memories.

\subsection{User consultation}

Three families who had not participated in the diary study, each consisting of mother, father, and one teenager (two 11-year-old girls and one 13-year-old boy), were consulted about the concepts. The concepts were discussed one by one, and a small interview for each concept consisted of questions addressing general opinion, the concept' ability to support communication, concept use, and possible improvements. The family members were further asked to determine their order of preference for the four concepts. Overall, the Timeline and Conversation Cubes were considered most interesting, although the drawing activities for the timeline concept were considered a threshold. This could be adjusted by allowing the use of images, but this in turn limits the possibilities of the concept. The Conversation Cubes were considered to have the right balance between being always present and accessible in the home and requiring active family involvement. Based on this feedback, the Conversation Cubes were selected and further developed in terms of functionality and design into the final concept, called Cueb.

\subsection{Final concept: Cueb}

Cueb is an interactive digital photo device with which parents and teenagers can explore individual and shared experiences and are triggered to exchange stories. By letting parents and teenagers go through photographs together, Cueb supports telling stories from the parents' past that are normally forgotten, because old photographs are, for example, stored in albums in the attic. Every family member has his or her own digital photo cube, which shows photographs on six sides. Shaking the cube displays random photographs of experiences this person had without the other family members. When connecting cubes and shaking them, photographs will be shown of experiences the owners of the connected cubes had together. Furthermore, when pressing a photograph inwards, this photograph will be locked and used as selection filter for themes of the photographs; for example, locking a photograph of a birthday party in the summer may generate other photographs of birthday parties or photographs taken in the summer. Finally, photographs can be switched between cubes by holding two cube sides together. A switched photograph can then be locked on another person's cube, allowing him or her to see photographs that are related to the experiences of the other person. With Cueb, parents and teenagers can explore photographs of their experiences and 
share stories. By switching and locking photographs, they can compare their experiences and identify similarities and differences.

A computer rendering of the final design can be seen in Fig. 5a. The inspiration for the design came from the wellknown traditional photo cubes and from the popular retro product look. In this way, the design represents a combination of old and new through its appearance and the technology used, which relates to its function of discussing memories from longer ago and recent ones.

\section{Implementation}

A working prototype was created for Cueb, see Fig. 1. To be able to test the interaction between the cubes, two cubes with three displays and three printed photographs each were created. Each cube had one interactive side that was fully functional and could be used to switch and lock photographs. The other two interactive sides could display digital photographs, and all six sides could be used to connect the cubes for shared experiences.

Each cube had a wooden body with a synthetic coating in which Plexiglas and imitation leather were incorporated to provide transitions between the body and the screens. On the fully functional side, the imitation leather provided the flexibility needed to push the screen inwards for locking a photograph. Inexpensive digital photo key chains were used to store and display photographs, and these were controlled with an Arduino Pro Mini [37]. Each cube incorporated an accelerometer to detect shaking. Magnetic connection points on the cubes' surfaces were used to detect connection of cubes and to provide, through a variable voltage, the required communication for switching photographs. For this prototype, the photographs that could be switched were already stored on both cubes, and by transferring photograph values, the cubes could navigate to the right photographs. The lock functionality was intended to be realized by using a keyword and metadata search resulting in a filtering functionality (the users would tag the photographs using a software application). In the prototype, this was not implemented; instead, the lock functionality generated a predetermined set of related photographs when a user locked a certain photograph. Figure $5 \mathrm{~b}$ shows the working Cueb set in the context these were designed for, namely the living room.

Although Cueb was developed as a research probe, we appreciate that the concept could be developed into a product. Families would then get a set of at least two cubes, but purchase of single cubes should be possible as well. Users involved in the evaluations of Cueb commented they would like to give the cubes as a gift to family or friends. A software tool would be provided with a cube to tag and upload photographs. It is likely that in a few generations, all family photographs will be digital, but currently many families have a large number of physical photographs, which need to be scanned first. In this increasingly digital age, some families involved in the project had already started scanning their photographs and slides, but there are also many families that have not done this. For successful inclusion of these physical photographs, we propose collaboration with a photograph scanning service, for example, by giving people who acquire Cueb an optional discount for having their photographs scanned. Since Cueb is primarily intended to be used within a family, it does not need a large uptake to be effective in its function. We envision use of Cueb would be most frequent during a period after acquiring it, but further use would be triggered by uploading new photographs and the possibilities of discovering new connections of these photographs to other photographs on the cubes.

\section{User evaluation}

The prototype set was used in a user evaluation with four families. From each family, a collection of photographs was obtained well before the evaluation took place, and we made selections of photographs to be used in the evaluations. In each family, one parent and one teenager were the primary users, who used the cubes and had their personal photographs on them. The other family members were free to join in on the conversations and the concluding interview. Photographs were selected from individual and shared experiences in different life phases, for example, individual experiences from the parent's youth, a parent's recent individual experiences, shared experiences in the teenager's childhood, and the teenager's individual
Fig. 5 a Computer rendering of the design of Cueb, $\mathbf{b}$ The prototype of Cueb in a living room
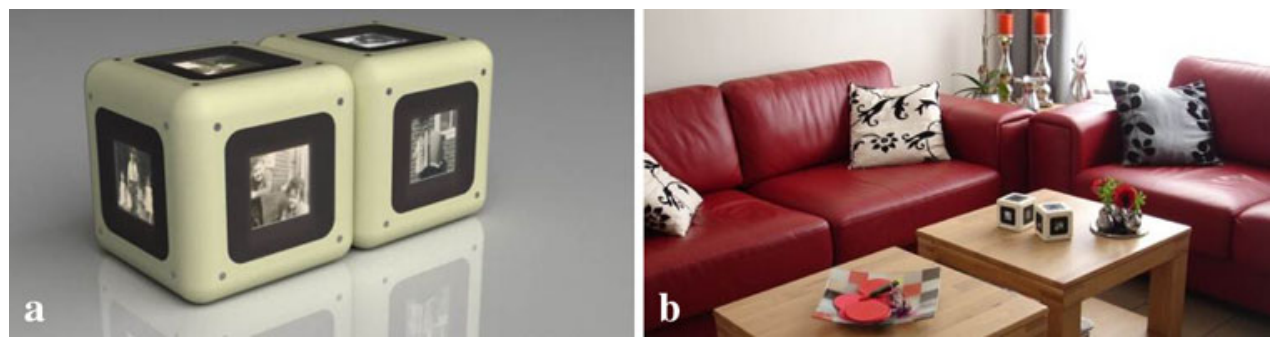
experiences. Related photographs were selected and grouped based on reoccurring themes like birthdays, holidays, or sports. The participants did not know which photographs were selected (and in some cases, the primary users did not even provide the photographs), so the prototype provided surprising, often forgotten photo results.

\subsection{Method}

The research question to answer was as follows: Does Cueb's interactive photo functionality facilitate parentteenager communication regarding sharing experiences and getting to know each other? To answer this question, we compared the use of Cueb to the use of a more traditional photograph viewing product in terms of functionality. Therefore, we compared Cueb with limited functionality (representing more traditional product functionality) to Cueb with full functionality, in a within-subjects experiment. In limited functionality situation, regular photo viewing and shaking the cubes were enabled. Because of the differences in functionality in the two conditions counterbalancing was not possible, but by using Cueb in both situations, the difference between the two situations caused by first-time enthusiasm about the new product was intended to be minimal. In the full-functionality situation, it was possible to use Cueb for: shaking, connecting to display shared experiences, switching photographs, and locking photographs. By comparing the two situations, we wanted to find out whether the lock, connect, and switch functions of Cueb have an additional value in facilitating communication, compared to showing only (random) photographs, which is comparable to digital photo frames. Our expectation was that Cueb with full functionality made it easier for family members to relate their experiences to other experiences of themselves and others, leading to discussions of these experiences. Thus, we expected that Cueb's extra functions compared to other photo products have a positive effect on everyday communication between parents and teens.

Although we acknowledge the advantages of a more longitudinal study, the prototype was not developed far enough to make this feasible: photographs and combinations of related photographs were pre-selected, and transferred photographs needed to be present on both cubes. The evaluations took place in the families' homes. For each condition in the user evaluation, a different photograph set was used, so that there was no prior knowledge of the photographs in each situation. Data were collected through questionnaires, a concluding interview, and observation by two observers. After a brief explanation of the design context and concept (without going into specifics about possibilities and interaction) and signing consent forms, the evaluation consisted of four parts, which in total took on average $1.5 \mathrm{~h}$ to complete.

\subsubsection{Part 1: sharing stories with random photograph input (photograph set 1)}

The participants were introduced to the cubes and were told that the cubes could be used to display their family photographs and that shaking them would display new photographs. They were asked to explore the photographs and share experiences with each other. The photograph set used in this situation consisted of 9 photographs, so that each screen could show three different photographs. Afterward, participants were asked to complete a questionnaire for this first situation. This questionnaire included statements about the concept's ability to trigger stories, provide handles to stories, and to help to get to know each other better. Participants were asked to rank their agreement to these statements on a 7-point Likert scale.

\subsubsection{Part 2: introduction of extra functionality (photograph set 2)}

In the second part, the cubes were fully functional, and participants received a short illustrated manual with the possibilities: shaking, connecting, switching, and locking. It was also explained that each cube contained the experiences of one person. After going through the manual, participants were asked to try the functions and explore possible outcomes. In this part, the focus lay on the interaction and getting to know the product.

\subsubsection{Part 3: sharing stories with full functionality (photograph set 2)}

The participants were again asked to use the prototype to explore their photographs and share their experiences. In this part, the cubes were fully functional and participants could use the extra functions. Afterward, the participants were asked to complete the questionnaire again for the second situation.

\subsubsection{Part 4: short concluding interview}

In the concluding part, the participants were asked (within the group) a short list of questions to test their general opinion on the concept. These questions included their opinions on the different functions, whether they would use it and how, and possible improvement points.

Four Dutch families, who had not participated in earlier stages of the study, participated in the user evaluations, of which both parents and one or two teenagers participated. In each family, there was a parent-teenagers couple (chosen by the families), whose photographs were on the cubes and who actually used the prototype in the intended way: the primary users. Other family members could 
participate in the communication and discussions, and were also asked to fill out the questionnaires and participate in the interview. These will be further addressed as secondary users. In total, 13 people took part in the user evaluations, of which 8 were primary users and 5 were secondary users, see Fig. 6.

The 11 statements in the questionnaire were divided into three groups: (1)—statements about cueing communication: including statements that addressed the effect of the concept on triggering or initiating stories or memories, (2) - statements about facilitating communication: including statements that addressed the effect of the concept on supporting storytelling, and (3) - statements about the parent-teenager relation: including statements that addressed the effect of the concept on family relations, such as getting to know parent or teenager, helping to empathize, or helping to open up to each other. The questionnaire results of the 8 primary users were used to compare the two situations.

\subsection{Evaluation results}

When comparing the questionnaire results of the two different functionality situations in the evaluation, it could be seen that in general, participants rated the statements low on the 7-point scale, where 1 meant "totally agree" and 7 meant "totally disagree", so they generally agreed with the concept's ability to support cueing and facilitating communication, and family relations. The mean over all statements for situation 1 was 2.13 and for situation 2 was 1.59. A Wilcoxon signed rank test showed there was a significant difference between the two situations: situation 2 (Cueb with full functionality) worked significantly better in cueing and facilitating stories and memories, and was believed to have a stronger positive effect on family relations than situation 1 (random photograph displaying) $(z=-2.296, p<0.05, r=-0.25$; this represent a small to medium effect). When looking at the statement groups separately, this effect appeared to be caused more by the "cue" and "relation" statement groups than by the "facilitation" group. See "Appendix" for a summary of the questionnaire results.
The observations during the sessions further showed that the participants were enthusiastic about Cueb, and they thought the interactive character made it more interesting than alternative photo media, such as photo albums, digital photo frames, and computers. One parent commented: "In a photo album you are always looking at the same events in sequence. This is much more surprising, it challenges my memory." Another parent commented: "Viewing photos behind the computer is not cozy, this is," and a third parent said: "I would put my photos on [the cubes] as soon as I made new ones. It takes some time, but it is definitely worth it." Shaking was considered an attractive interaction and was used frequently to keep the communication going. A mother exclaimed: "This is so much fun! I could do this for ages." In most families a process of turn taking arose to not miss any photographs or opportunities for sharing stories: for example, "Now let's see what you've got, son." The photographs also triggered laughter, especially teenagers appeared to have fun looking at photographs from their parents they had not seen before: "Look at your hair! I never knew you used to wear such a funny wig!" It could be seen that Cueb triggered and facilitated communication about both shared experiences: for example, teenager: "what am I wearing here?" Mother (laughing): "that is a robot mask you had made." Father: "No, it was Spiderman." Teenager: "Oh, I remember that!", and individual experiences, for example teenager: "Here I was lying in the bus at school camp." Dad: "What are you doing there?""Sleeping." - "I can see that, tell me more."_-"There were four of us. I was sitting here, next to Denise, Ilya and Audrey and we were all lying in a heap, sleeping." "Were you really sleeping?"- "Yes. And Bram had his sunglasses dangling from his nose as he was lying there, and his cap on backwards. Honestly, it was so stupid. We took a picture of that; it was so stupid.", as well as comparing experiences. One family, for example, compared current teenager parties to those in the past; parent: "Back then it was normal to put packs of cigarettes on the tables for everyone to use." Teenager: "Did you smoke as well?"_-“Yes, everybody did it."__"Yuck!” Both parents and teenagers were actively involved and interested in the other party's stories. In the sessions, the stories were
Family 1

\begin{tabular}{|c|c|}
\hline \multicolumn{2}{|l|}{ Primary users } \\
\hline Father (49) & Son (14) \\
\hline \multicolumn{2}{|l|}{ Secondary users } \\
\hline Mother (43) & \\
\hline
\end{tabular}

Family 2

\begin{tabular}{|l|}
\hline Primary users \\
Mother (49) Daughter (15) \\
\hline Secondary users \\
Father (53) \\
\hline
\end{tabular}

Family 3

\begin{tabular}{|c|c|}
\hline $\begin{array}{l}\text { Primary users } \\
\text { Mother (39) }\end{array}$ & Son (12) \\
\hline \multicolumn{2}{|c|}{ Secondary users } \\
\hline Father (38) & Daughter (10) \\
\hline
\end{tabular}

Family 4

\begin{tabular}{|l|}
\hline Primary users \\
Father (50) Daughter (11) \\
\hline Secondary users \\
Mother (39) \\
\hline
\end{tabular}

Fig. 6 Overview of the families, primary and secondary users in the user evaluation 
mainly quite short, and participants, for example, checked location, time, or people on the photographs with each other, for example, "Where was this again?"; "That was a nice holiday right?"; or "Oh look, this is your dad's ex-girlfriend." Also in some families a quiz-like communication arose, testing each other's knowledge about the experiences on the photographs; dad: "Do you where this is?" Teenager: "Yes!"- "Where?"- "When I got my swimming certificate! [...] And this one, dad?"- "Where was that taken?"-_ "I remember."_- "Yes, me too. I think 2 months ago, right, when we were on holiday?"_- "Yes!" Both shared and individual experiences were discussed, and it was clear to see that while conversations about shared experiences took the form of shared reminiscence, conversations about individual experiences took more the form of storytelling, as also found by Frohlich et al. [24], for example, a father telling his son about a house he had built: "Oh, here I dug a huge hole in my first house." Teenager: "Yeah, I know that"—-No, you don't know that, you weren't there. I didn't even know your mum then."- "Where is that then?"_- "In [place name]. I build a house there and when it was finished I sold it."- "For more money than you spent building it?"_- No, that's not the point, erm, no not even that."

Communication about the past of the parents was also facilitated, and teenagers appeared interested in this. These conversations addressed, for example, parents' past work, holidays, friends, or pets: for example, dad: "This was at my old job, that's a really long time ago... That's maybe..." Teenager: "32 years ago?"-_No, 15, 16 years ago, I think. Every year we had this garden party and here I am frying the meat for my colleagues." — "Really nice, I didn't know that!" Working with the prototype and communicating about the photographs appeared to be pleasurable, and participants showed much enthusiasm in working with the different functions:- "Shall we switch a photo?"- "Yes, I want that one with your dog to lock it!" The second situation, with full functionality, appeared to initiate slightly more and more elaborate communication than the first, and participants particularly liked to be able to compare their experiences through the combination of switching and locking. A mother commented: "I see now that we've been to the sea a lot. It is nice to see that [my son] already has had so many experiences similar to mine."

Additional features and points for improvement mentioned by participants included: having bigger photographs or being able to see them at a larger separate screen, for example, on TV, the possibility to choose from different colors or prints or have all cubes in a set in a slightly different design, photographs could rotate along with the cubes, a slideshow when a cube is idle in a room, and the gaming element could be expanded, for example, using the cubes as dice.
From these observations and remarks, it can also be concluded that Cueb does facilitate communication about the parents' past in a pleasurable way. Also, the goal of activity involving the teenagers has been met by introducing an interactive product, which they appeared interested in exploring and using. One teenager commented: "It is very nice to play with and it is new every time, it keeps me going on."

\section{Discussion}

Our user evaluation showed that Cueb gives parents handles to share their past with their teenagers. From our research, it appeared that parents do not often discuss their past with their children. Cueb can make parents aware of their children's curiosity and communicate about their mutual interests. To trigger questions and memories, Cueb uses digital photographs. This is in line with the theory behind augmented memory systems [e.g., 23]: the system or product stores cues that are used to retrieve memories. Cueb merely triggers, and a family member constructs the memory and communicates about it. Cueb provides flexibility in photograph combinations. This allows family members to construct their own memories around photographs, which can be different from the actual event, for example, adapted to the audience.

The childhood and past photographs of the current generation of parents are mostly in the physical format. These physical photographs are often put in albums and placed in a cupboard or in the attic. Parents in our study indicated they hardly ever take these photographs out to look at them, and teenagers indicated that they had not seen their parents' photographs before. For our study, we digitized these old photographs and through an interactive product brought them into the daily environment of families as a means for storytelling. Cueb can be placed on the living room table and trigger use from time to time, from individual family members or when family members are together. Through its symmetrical design, it can do this in any direction. Cueb leaves room for parent-oriented communication, an often neglected area in parent-teenager communication, and gives parents and teenagers the opportunity to choose their preferred way of communicating; for example, a teenager can be triggered by a photograph (s)he sees on a parent's cube and ask about it later while doing another activity with the parent. Alternatively, parent and teenager may engage in sit-down conversations about the photographs on the cubes. It is also likely that when parents and teenagers engage in tagging photographs together to use them with Cueb, this provides a good opportunity to spend time together and talk about experiences and content of photographs. In this way, Cueb 
combines the roles of a passive photograph display and an active family photograph viewing device and supports the various ways in which parents and teenagers want to communicate.

Cueb incorporates a separate, portable product for each family member instead of a large installation with which they interact together, for example, a table top application. This has its advantages and disadvantages. On the one hand, family members may choose to use their cubes individually, limiting social interaction and communication. On the other hand, separate products give family members the chance to select what photographs to share with others, choosing, for example, the best memories. Furthermore, when sharing photographs, the size of the cubes makes family members lean closer to each other to see the photographs, creating an intimate, confidential feeling through their body language. Finally, the shared functions (connecting, switching photographs) make it interesting to work together to create new results and facilitate continuing communication.

Compared to the currently popular digital photo frames, Cueb is more interactive and surprising, because of its functionality (shaking, connecting cubes, switching, and locking photographs), and it can, thus, initiate a family activity, in which family members are actively viewing photographs and exchanging stories. Compared to a computer, Cueb has less photo functionalities, such as zooming, searching, organizing, but it is placed more in the daily family environment, and family members commented it is more inviting. When comparing Cueb to traditional photo albums or collections, it can be concluded that some affordances of these physical media have been lost, such as the lay-out of an album page, traces of time and usage (e.g., stains or folds), or added notes about the photographs. However, these are replaced by affordances of the digital media, such as interactivity, ease of use, and the ability to back-up and copy photographs. Furthermore, for the current and future generations of teenagers, who have grown up using computers, an interactive product is likely to appeal more than a static photo album. An interesting observation in the user evaluation was that in some families, the teenager actually had an extra function in the interaction with Cueb, namely helping his or her parents working with the technology. This can be beneficial for the parent-teenager relationship as the teenagers may feel knowledgeable and taken more seriously when they can fulfill such a function. Furthermore, Durrant et al. [32] found that while teenagers value being represented in curated photo display, they also desire flexible, autonomous photo display. Cueb represents curated photograph control and family photograph representation through connecting cubes and displaying shared photographs, while it also gives teenagers their own personal cube, which they can update and change as they please. Further Cueb supports the wish for tangibility of digital photographs for selfpresentation expressed by some teenagers in Durrant et al.'s study. All in all, we acknowledge the affordances of both the physical and the digital media and propose Cueb not as a replacement of physical photo albums, but as an addition.

Apart from being an interesting product for teenagers because of its interactive nature, parents indicated it was also especially valuable during adolescence, because teenagers start to do their own activities, for example, their first holiday without parents. For the parents, this is also a phase of adjustment, and with Cueb, they can share experiences by comparing photographs of their holidays in their teenage years with their child's. Furthermore, we assume Cueb can support the metaphor of growing up and becoming more independent during the teenage years. After all, a child's cube, when not connected to parents' or siblings' cubes, only shows the experiences the teenager has done without the other family members. When the child is young, most of its experiences are together with its parents, so the child's cube will not have many photographs of individual experiences. In teenage years, the child starts to do more and more activities without its parents and more photographs of individual experiences can be put on the cube. Thus, as a person develops from childhood to adulthood, his or her cube grows along through the photograph collection on it. In an ideal situation, Cueb can even be used in multiple generations: as the child grows up and leaves home, he or she can take the cube and use it again with his or her children and their grandparents. All in all, it can be concluded Cueb provides interesting possibilities, which appear to be especially valuable for parents with teenagers, because that appears to be the age when children get interested in their parents' past.

\section{Conclusion}

In this paper, we identified design opportunities for supporting parent-teenager communication in the home. With a diary study, we identified that everyday parentteenager communication is quite mundane and does not often address the topics most addressed in literature, such as sex, drugs, alcohol, or smoking. Within the broad diversity and range of parent-teenager communication, we focused on a facet of everyday communication. We found a mismatch between actual communication and desired communication regarding getting to know the parents and their past, and we have designed an interactive photo medium, Cueb, accordingly. From a comparison between Cueb with full functionality (allowing for connecting 
parent's and teenager's cubes, switching photographs between cubes and locking photographs, thereby filtering the search) and Cueb with limited functionality (allowing for random photograph results by shaking the cubes, which is comparable to a more traditional photograph medium), we conclude that Cueb's full functionality works significantly better in cueing and facilitating parent-teenager communication about the parent's past.

Acknowledgments We thank all families that have participated in the diary study, concept consultation, and user evaluation for their valuable feedback, our colleagues at the Industrial Design department for their expertise and support, Femke Huskens and Frederiek van der Ploeg for their roles as clients and experts, the other staff members at Centrum voor Jeugd en Gezin Sittard-Geleen, Lumens groep, and Welzijn Eindhoven who have participated and advised in various stages of the study, De La Roy for the prototype coating, and Elma van Vliet for her insights on the study and concepts.

Open Access This article is distributed under the terms of the Creative Commons Attribution Noncommercial License which permits any noncommercial use, distribution, and reproduction in any medium, provided the original author(s) and source are credited.

\section{Appendix: summary of questionnaire results}

The questionnaire consisted of 11 statements. After each situation in the user evaluation, participants were asked to rate their agreement to each statement on a 7-point Likert scale. The statements in the questionnaire were ("the concept" is here the prototype used in that situation):

1. The concept does not stir up stories with me.

2. The concept gives me handles for telling my story.

3. The concept inspires me.

4. The concept does not evoke memories.

5. The concept brings up stories that otherwise would be left untold.

6. The concept does not help me to tell stories.

7. The concept helps me to get to know my parent/ teenager better.

8. The concept helps me to open up to my parent/ teenager.

9. The concept does not help me to understand my parent/teenager better.

10. The concept helps me to empathize with my parent/ teenager.

11. The concept does not help me to see the similarities between my parent/teenager and me.

These statements were divided into three groups: 1statements about cueing communication: including statements that addressed the effect of the concept on triggering or initiating stories or memories (Cue: statements 1,3,4, and 5), 2-statements about facilitating communication: including
Table 2 Means of ranking and standard deviations for situations 1 and 2

\begin{tabular}{|c|c|c|c|c|}
\hline \multirow[t]{2}{*}{ Statements } & \multicolumn{2}{|l|}{ Situation 1} & \multicolumn{2}{|l|}{ Situation 2} \\
\hline & $\begin{array}{l}\text { Teenagers } \mu \\
(\sigma)\end{array}$ & $\begin{array}{l}\text { Parents } \mu \\
(\sigma)\end{array}$ & $\begin{array}{l}\text { Teenagers } \mu \\
(\sigma)\end{array}$ & $\begin{array}{l}\text { Parents } \mu \\
(\sigma)\end{array}$ \\
\hline \multicolumn{5}{|l|}{ Cue } \\
\hline 1 & $1.75(0.96)$ & $1(0)$ & $1.13(0.50)$ & $1(0.50)$ \\
\hline 3 & $2.75(1.26)$ & $3(2.71)$ & $2.63(1.71)$ & $2(1.71)$ \\
\hline 4 & $3.25(2.63)$ & $2.75(2.87)$ & $1.88(0.82)$ & $1.75(0.82)$ \\
\hline 5 & $1(0)$ & $1(0)$ & $1(0)$ & $1(0)$ \\
\hline \multicolumn{5}{|l|}{ Facilitation } \\
\hline 2 & $2.75(1.26)$ & 3. (1.83) & $2(1.50)$ & $1.25(1.50)$ \\
\hline 6 & $2.5(1.29)$ & $1.25(0.50)$ & $1.63(1.41)$ & $1.25(1.41)$ \\
\hline \multicolumn{5}{|l|}{ Relation } \\
\hline 7 & $2.25(1.26)$ & $4(1.41)$ & $2.25(2.38)$ & $2(2.38)$ \\
\hline 8 & $3.75(2.06)$ & $2.75(0.96)$ & $2.25(1.50)$ & $1.25(1.50)$ \\
\hline 9 & $1.75(0.5)$ & $5(1.41)$ & $2.50(1.29)$ & $2.50(1.29)$ \\
\hline 10 & $3.5(2.52)$ & $2.25(1.50)$ & $3.38(2.08)$ & $3.25(2.08)$ \\
\hline 11 & $2.75(1.50)$ & $2.75(2.87)$ & $1.88(1.29)$ & $1.25(1.29)$ \\
\hline
\end{tabular}

For negative statements, $1,4,6,9$, and 11 scales were inverted for comparison

statements that addressed the effect of the concept on supporting storytelling (Facilitation: statements 2 and 6), and 3-statements about the parent-teenager relation: including statements that addressed the effect of the concept on family relations, such as getting to know parent or teenager, helping to empathize, or helping to open up to each other (Relation: statements $7,8,9,10$, and 11).

Table 2 gives an overview of the questionnaire results for situations 1 (random photograph displaying) and 2 (Cueb with full functionality), for parents and teenagers, and for the three statement groups.

\section{References}

1. Noller P, Bagi S (1985) Parent-adolescent communication. J Adolesc 18:125-144

2. Henry CS (1994) Family system characteristics, parental behaviors, and adolescent family life satisfaction. Fam Rel 43:447-455

3. Noller P, Callan VJ (1990) Adolescents' perceptions of the nature of their communication with parents. J Youth Adolesc 19(4): 349-362

4. Jaccard J, Dittus PJ, Gordon VV (2000) Parent-teen communication about premarital sex: factors associated with extent of communication. J Adolesc Res 15:187-208

5. Rosenthal DA, Feldman SS (1999) The importance of importance: adolescents' perceptions of parental communication about sexuality. J Adolesc 22:835-851

6. Richardson RA (2004) Early adolescence talking points: questions that middle school students want to ask their parents. Fam Rel 53:87-94 
7. van den Hoven E, Frens J, Aliakseyeu D, Martens J-B, Overbeeke K, Peters P, Design research \& tangible interaction (2007) In: Proceedings of TEI 2007, ACM Press, New York, pp 109-116

8. Noller P (1994) Relationships with parents in adolescence: process and outcome. In: Montemayor R, Adams GR, Gullota TP (eds) Personal relationships during adolescence. Sage, Thousand Oaks, pp 37-77

9. Jackson S, Bijstra J, Oostra L, Bosma H (1998) Adolescents' perceptions of communication with parents relative to specific aspects of relationships with parents and personal development. J Adolesc 21:305-322

10. Kirkman M, Rosenthal DA, Feldman SS (2002) Talking to a tiger: fathers reveal their difficulties in communication about sexuality with adolescents. New Dir Child Adolesc Dev 97:57-74

11. Lefkowitz ES (2002) Beyond the yes-no question: measuring parent-adolescent communication about sex. New Dir Child Adolesc Dev 97:43-56

12. Miller-Day MA (2002) Parent-adolescent communication about alcohol, tobacco, and other druguse. J Adolesc Res 17:604-616

13. Hummels CCM, Overbeeke CJ, Appleby RS, Frens JW, Wensveen SAG (2008) The power of embodiment for design and vice versa. Form + Zweck 22:6-11

14. Durrant A, Taylor S, Frohlich D, Sellen A, Uzzell D (2009) Photo displays and intergenerational relationships in the family home. In: Proceedings of BCS-HCI 2009, ACM Press, New York, pp 10-19

15. Casson J, Communicube and Communiwell (2002). http://www. communicube.co.uk. Last accessed 14 Nov 2011

16. Kim J, Zimmerman J (2006) Cherish: smart digital photo frames for sharing social narratives at home. Ext. Abstracts CHI 2006, ACM Press, New York, pp 953-958

17. Blechman EA (1974) The family contract game. Fam Coord 23(3):269-281

18. Khoo ET, Lee SP, Cheok AD, Kodagoda S, Zhou Y, Toh GS (2006) Age invaders: social and physical inter-generational family entertainment. Ext. Abstracts CHI 2006, ACM Press, New York, pp 243-246

19. Romero N, Markopoulos P, Baren J, Ruyter B, Ijsselsteijn W, Farshchian B (2007) Connecting the family with awareness systems. Pers Ubiquit Comput 11(4):299-312

20. Mynatt ED, Rowan J, Jacobs A, Craighill S (2001) Digital family portraits: supporting peace of mind for extended family members. In: Proceedings CHI 2001, ACM Press, New York, pp 333-340

21. Conway MA, Rubin DC (1993) The structure of autobiographical memory. In: Collins AF, Gathercole SE, Conway MA, Morris PE (eds) Theories of memory. Psychology Press, Hove, pp 103-137
22. Guenther RK (1998) Human cognition. Upper Saddle River, Prentice-Hall

23. van den Hoven E, Eggen B (2008) Informing augmented memory system design through autobiographical memory theory. Pers Ubiquit Comput 12(6):433-443

24. Frohlich D, Kuchinsky A, Pering C, Don A, Ariss S (2002) Requirements for photoware. In Proceedings of CSCW 2002, ACM Press, New York, pp 166-175

25. Balabanovic' ${ }^{\prime}$, Chu LL, Wolff GJ (2000) Storytelling with digital photographs. In: Proceedings of CHI 2000, ACM Press, New York, pp 564-571

26. West D, Quigley A, Kay J (2007) MEMENTO: a digital-physical scrapbook for memory sharing. Pers Ubiquit Comput 11(4):313328

27. Shen C, Lesh N, Vernier F (2003) Personal digital historian: story sharing around the table. Interactions 10(3):15-22

28. Kirk DS, Izadi S, Sellen A, Taylor S, Banks R, Hilliges O (2010) Opening up the family archive. In: Proceedings of CSCW 2010, ACM Press, New York, pp 261-270

29. van den Hoven E, Eggen B (2003) Digital photo browsing with souvenirs. In: Proceedings of Interact 2003, IOS Press, Amsterdam, pp 1000-1003

30. Nunes M, Greenberg S, Neustaedter C (2009) Using physical memorabilia as opportunities to move into collocated digital photo-sharing. Int J Human Comput Stud 67(12):1087-1111

31. Swan L, Taylor AS (2008) Photo displays in the home. In: Proceedings of DIS 2008, ACM Press, New York, pp 261-270

32. Durrant A, Frohlich D, Sellen A, Lyons E (2009) Home curation versus teenage photography: photo displays in the family home. Int J Human Comput Stud 67(12):1005-1023

33. Feldman SS, Rosenthal DA (2000) The effect of communication characteristics on family members' perceptions of parents as sex educators. J Res Adolesc 10:119-150

34. Youniss J, Ketterlinus RD (1987) Communication and connectedness in mother- and father-adolescent relationships. J Youth Adolesc 16(3):265-280

35. Kernis MH, Brown AC, Brody GH (2000) Fragile self-esteem in children and its associations with perceived patterns of parentchild communication. J Pers 68:225-252

36. Walker LS, Greene JW (1986) The social context of adolescent self-esteem. J Youth Adolesc 15(4):315-322

37. Arduino, Official website: http://www.arduino.cc/. Last accessed 14 Nov 2011 